\title{
The impact of audio-visual technologies on university teaching and learning in a developing economy
}

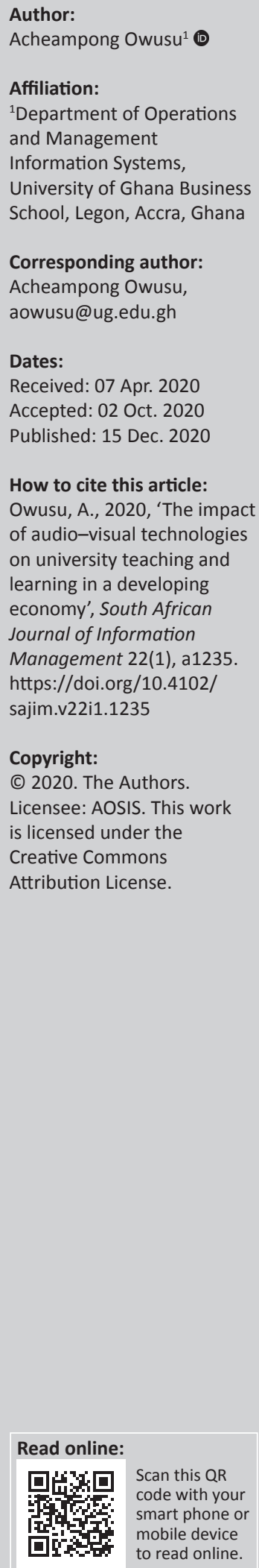

Background: The use of audio-visual (AV) technologies for teaching and learning is a longestablished phenomenon. Thus, a lot has been said about its impact on teaching and learning. Yet, most of these studies have focused on developed economies with a dearth of literature from developing economies context, especially in sub-Saharan Africa. This study attempts to fill the gap in the literature.

Objectives: This study assesses the impact of a school's AV technologies on teaching and learning through the lens of the DeLone and McLean Information Systems Success Model.

Method: The study adopted the survey technique of quantitative research. Data collection was performed through questionnaires designed in conjunction with six constructs (AV Information Quality, AV System Quality, AV Service Quality, AV System Use, User Satisfaction and Net Benefits) in which 432 valid samples were subjected to confirmatory factor analysis to establish the reliability and validity of the constructs. Inferential data analysis was performed through structural equation modelling to establish the causal relationship between the hypothesised constructs.

Results: The result of this study established that, except for the relationships between information quality and system use and the relationship between system use and net benefits, the other hypothesised relationships were all found to have positive direct relationships.

Conclusion: The level of significance resulting from the analysis provides insight into the need for instructors and systems designers to make a conscious effort in improving learner's satisfaction by concentrating more on the antecedent of user satisfaction. This research provides insight into the implementation success of the school's AV technologies from students' perspectives. It also provides a strong theoretical underpinning and a multivariate data analysis, which are lacking in the literature.

Keywords: AV technologies; business school; DeLone and McLean Information Systems Success Model; structural equation modelling; university.

\section{Introduction}

The key to individual success and progress at all levels of educational development is the act of teaching and learning (Ode 2014). Hence, a well-planned and directed process is essential for an effective teaching and learning process (Lari 2014). For this reason, Ode (2014) argues that teaching aids that are commonly denoted as audio-visual (AV) tools need to be adopted to enhance the process. Indeed, from an instructor's and a student's perspective, research has confirmed that using AV technologies for teaching and learning has positively affected teaching (Lari 2014; Mathew \& Alidmat 2013; Ode 2014). Ode (2014) emphasises that 'attention, motivation, concentration, and retention of facts are enhanced through the use of audio-visual materials'. Lari (2014) also posits that technology plays a vital role in today's pedagogy and it draws student's attention. This can enhance effective means of learning when technology is used in classrooms.

Since its inception, studies on the impact of AV tools on teaching and learning have garnered some empirical examination. An examination of these studies has revealed that although salient gaps still exist in the current literature, constructive insights have been unearthed to support the usage of these tools (Asadi \& Berimani 2015; Seçer, Şahin \& Alc1 2015; Waheeda \& Murthy 2015). However, results from these studies have been inconsistent. For example, a study by Waheeda and Murthy (2015:11) compared blackboard teaching with PowerPoint (PPT) teaching from VMKV Medical College, Salem, India. Their results indicated that 'blackboard has the advantage of better recall besides being the most preferred aid among medical students'. Similarly, Asadi and Berimani (2015) evaluated the influence of AV tools on 'Iranian Second Grade High 
School Students' Language Achievement' and their results indicated that:

[T]he students in the experimental group performed better than the students in the control group in their language achievement. Thus, they concluded that the role of AV materials in teaching high school English textbook 2 to students led to a higher level of improvement in students' motivation and language achievement. (p. 69)

Also, Chavan et al. (2014) conducted a survey to investigate medical students' perceptions concerning the use of AV aids (chalkboard, overhead projector with transparencies and PPT lecture on liquid crystal display (LCD) during lecture sessions in Rural Medical College, Loni, India. Using a sample size of 200 students, their results indicated that 'chalkboard was the most preferred method by the students. Students in the primary phase preferred PPT lectures but students in the terminal phase preferred chalkboard'. Other AV studies (Asadi \& Berimani 2015; Seçer et al. 2015; Waheeda \& Murthy 2015) have pointed out its impact on teaching and learning in different geographical contexts and varying subjects at different levels of the educational ladder, but all these studies gave divergent results with no consensus (Mathew \& Alidmat 2013). These revelations suggest the need for more studies on AV tools that would consolidate these identified differences. Additionally, none of these studies were grounded on established theory (Lari 2014; Ode 2014; Secer et al. 2015), and no study has attempted to evaluate the implementation success of the AV tools. Moreover, an interpretation of the scope of the extant literature on the subject reveals that research has been concentrated in parts of Europe, the Middle East and Asia, confirming the apparent paucity of research performed in sub-Saharan Africa (Mathew \& Alidmat 2013; Secer et al. 2015). In the case of Ghana, presently, there is a dearth of research that examines the $\mathrm{AV}$ tools being used in our institutions. Therefore, we do not know the impact of these tools on teaching and learning in Ghanaian institutions. Considering the varying results from the impact in different geographic contexts, those results cannot be used in the Ghanaian context. Thus, the need to assess the impact of AV tools on teaching and learning in Ghana is appropriate.

To achieve this aim, the researcher adopted a theoretical stance by using the updated DeLone and McLean Information Systems (IS) Success Model (Delone \& McLean 2003), backed by a powerful statistical analysis (structural equation modelling [SEM]), to evaluate the implementation success of the AV tools being used by a business school of a public university in Ghana in order to ascertain if these tools are having a positive effect on teaching and learning. To enhance the interactivity and effectiveness of teaching and learning, the school has fixed world-class AV technologies in all its ultra-modern lecture theatres or classrooms and instructional laboratories, with the objective of not only facilitating lecturers' primary task of imparting knowledge but also augmenting the resources required to achieve this objective, making classroom teaching-learning process interesting and resourceful. The use of Microsoft PowerPoint slides or other presentation tools, the Internet, LCD projectors, amplifiers, microphones, speakers and so on, have helped solve the problems of lecturers having to shout during lectures and have made it easier for students to access lecture notes and also hear the lecturers clearly.

However, as with any system, evaluation of the effectiveness and impact of these AV tools on teaching and learning is essential if there is a need for further enhancements. Understanding this will help the management get a better insight into what steps need to be taken regarding the use of $\mathrm{AV}$ technologies in the school and whether the use of these tools have had a significant impact on teaching and learning. Such empirical evidence can also be used by educational policymakers and the government for replication in other tertiary institutions in the country to enhance teaching and learning, which can lead to more knowledgeable graduates that are churned out from the country's tertiary institutions.

The rest of the article is organised as follows: a literature review comprising the definition of $\mathrm{AV}$ tools, theoretical background and conceptual model with the development of hypotheses. It is then followed by the methodology, data analysis, discussion of findings and conclusions comprising recommendations and suggestions for future studies.

\section{Literature review}

\section{Audio-visual tools}

The International Federation of Library Associations and Institutions defines $\mathrm{AV}$ as 'any material(s) that pertain to sight and/or sound' (IFLA 2007, as cited in Seçer et al. 2015). In other words, AV aids can be described as 'any device which by sight and sound increase the individuals' experience, beyond that acquired through reading' (Rasul, Bukhsh \& Batool 2011). The label 'AV' consists of two words, that is 'audio', which refers to those materials that can be heard (e.g. radio, microphones, amplifiers and speakers), and 'visual', which refers to those materials that can be seen (e.g. chalkboard and whiteboard, overhead projector, LCD projectors, wall pictures and wall posters, picture flashcards, Word flashcards, Realia, videos or films and TV) (Asadi \& Berimani 2015; Mansourzadeh 2014). These AV tools and their use at schools have become an important part of teaching and learning in educational institutions (Seçer et al. 2015).

The AV technologies come in various formats and can be categorised as both electronic and non-electronic. Examples of electronic AV tools include personal computers, LCD projectors, amplifiers, speakers, DVDs, microphones, smart boards, slides, tape recordings, flashcards and discs, amongst others. The list for non-electronic AV tools includes black- or whiteboards and chalks or markers, filmstrips, microforms, transparencies, arts and study prints, projected opaque materials, charts, maps, atlases, posters, photographs, billboards, textbooks, etc. The non-electronic AV materials used in classrooms constitute what has been commonly referred to as the traditional approach to teaching and learning, which is still predominant in institutions in most 
developing economies because of its low affordability, inadequate electricity supply, and its ease of use and handling compared to the electronic ones, which require additional training and cost (Spencer 2017). Whilst the electronic AV tools (especially computers, LCD projectors and public address systems) are now gaining ground and emerging in most developing economies institutions, the intent informing its use is not to eliminate the traditional approach but rather to supplement it (Ashaver \& Igyuve 2013).

A review of extant literature has revealed that several studies have evaluated the impact of AV technologies on teaching and learning through experimental research, where both the electronic and non-electronic AV technologies have been compared to ascertain the best approach for teaching and learning (De Sousa, Richter \& Nel 2017). Others have also surveyed the AV tools to solicit students' or lecturers' views on the best approach when it comes to teaching and learning in different geographical contexts (Kumar et al. 2013; Nirmalya, Kaushik \& Rituparna 2015). For instance, seeking to find out the preferred AV technologies amongst first-year medical students in India, Nirmalya et al. (2015) revealed that the students favoured the mix of technologies. In other words, the authors stated that the respondents preferred a combination of visual aids during lecture periods. In another study that sought to explore the views of students with regards to the use of visual aids in a didactic lecture in India, Kumar et al. (2013) stated that students appreciate lectures delivered through a combination of AV technologies. De Sousa et al. (2017) have argued that the use of AV technologies brings teaching methods into the 21st century, supporting the student to catch the dream of success. Moreover, its adoption does not affect student learning when assessing knowledge and application outcomes. Again, in another study, Santos Espino, Afonso Suárez and González-Henríquez (2020:1) explored the 'use of digital videos in education', from the viewpoint of 'the teacher as an agent of technological integration'. Their findings indicate that 'secondary teachers make more use of digital video and are more innovative than university teachers'. Also, Ibe and Abamuche (2019:1) studied the 'effects of audiovisual technological aids on students' achievement and interest in secondary school biology in Nigeria'. Their results show that the 'group exposed to lessons with Audiovisual technological contents integrated achieved higher in test scores than the group not exposed to'. Moreover, Akhmetshin et al. (2019:374) studied '[a]udiovisual aids application in the secondary-level vocational education establishments' and their findings led them to conclude that:

[A] udiovisual aids application quality can be improved only through the research on students' educational and creative potential, their perception of various learning materials, and their preferences in the information structure, composition, types, and forms. (p. 374)

Likewise, Jose et al. (2019:316) studied the 'impact of lecture delivery by using PowerPoint presentation and blackboard and chalk in second year MBBS students in Pharmacology'. Their findings concluded that 'a majority of the students preferred lecture delivery using PowerPoint to blackboard and chalk'.

\section{Theoretical background}

This study was underpinned by the IS Success Model. The IS Success Model was originally developed by DeLone and McLean (1992). However, because of considerable criticisms and suggestions by various scholars for its enhancement, they developed the updated DeLone and McLean IS Success Model in 2002-2003 and that is what underpins this study. The updated DeLone and McLean IS Success Model (2003) has six main constructs, namely, information quality, system quality and service quality as the main independent variables and intention to use or actual use, user satisfaction and net benefits as the main dependent variables.

The updated DeLone and McLean IS Success Model (2003) posits that information quality, service quality and system quality of a given system will have a positive significant influence on the user's intention to use the system or actual system use, which can lead to user satisfaction. Likewise, the independent variables of a given system will have a positive significant influence on user satisfaction, which can lead to the user's intention to use the system or actual system use. Furthermore, the theory posits that intention to use or system use and user satisfaction can all lead to net benefits. The authors also explain that the intention to use or acual use can lead to user satisfaction. Conversely, the theory argues that once users are satisfied, they will also continue to use the system. Also, once users obtain benefits as a result of system use and user satisfaction, they will continue to use the system and also be satisfied. The updated DeLone and McLean IS Success Model has received a lot of attention from various technological innovation assessments. For example, 'assessing learning management success in higher educational institutions (HEIs)' (Mtebe \& Raisamo 2014), 'adoption behaviour for In-Car GPS navigation systems' (Hsu \& Lin 2010), 'adoption of web-based learning management systems' (Lwoga 2014) and 'understanding the impact of $\mathrm{m}$-banking on individual performance' (Tam \& Oliveira 2016). Also, because of its popularity, it has received over 12000 citations in Google Scholar (Delone \& McLean 2003).

\section{Conceptual model}

Figure 1 shows the research model developed for this study based on the Delone and McLean (2003) IS Success Model and existing literature.

\section{Audio-visual information quality}

Information quality (INFOQUAL) is defined as 'the degree to which a user perceives that the information output' of the system under investigation is 'complete, accurate, wellformatted, and timely' (Delone \& McLean 2003; Hsu \& Lin 2010). This signifies that students expect to see the information resulting from $\mathrm{AV}$ technologies in the University's lecture rooms to be complete and highly visible. Students also use AV technologies for their presentations. Therefore, they also expect the output from their presentations to be of high quality to garner the needed 


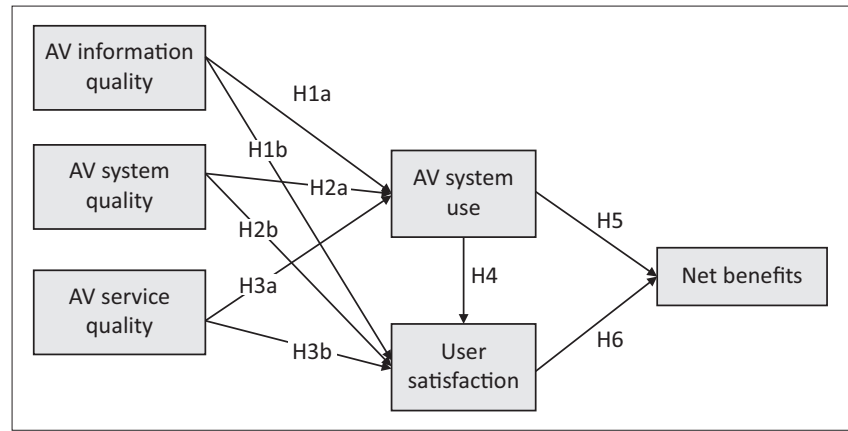

Source: Author's own development based on the IS Success Model of Delone, W.H. \& McLean, E.R., 2003, 'The DeLone and McLean model of information systems success: A tenyear update', Journal of Management Information Systems 19(4), 9-30. https://doi.org/ 10.1080/07421222.2003.11045748

AV, audio-visual.

FIGURE 1: Audio-visual implementation success: Research model and hypothesis development.

marks expected. This complete information is expected to lead to AV system acceptance as well as user satisfaction from students. In the context of this study, information quality is renamed 'AV Information Quality' and that is what is being examined. Many studies in the IS literature across various sectors and evaluation of different technologies have found a positive significant relationship between information quality and system use as well as between information quality and user satisfaction (Chen et al. 2015; Hsu \& Lin 2010; Hu 2015; Mohammadi 2015; Mtebe \& Raisamo 2014; Rana et al. 2015; Tam \& Oliveira 2016). The researcher, therefore, hypothesised that:

H1a: AV Information Quality will positively influence AV System Use

H1b: AV Information Quality will positively influence User Satisfaction

\section{Audio-visual system quality}

System quality (SYSQU) is defined as 'the degree to which a user perceives that the system under scrutiny is easy to use, reliable, responds quickly, amicably, and flexibly' (Delone \& McLean 2003; Hsu \& Lin 2010). Thus, the reliability and userfriendliness of the AV technologies in lecture rooms are expected to lead to AV system acceptance and user satisfaction. As students also use AV technologies for their presentations during weekly seminar series, where they present their research progress and other oral examinations, their views on the systems are also being solicited in this study. In the context of this study, system quality is renamed 'AV System Quality' and that is what is being examined. Several studies have established that there is a positive significant relationship between system quality and system use as well as between system quality and user satisfaction (Chen et al. 2015; Hsu \& Lin 2010; Hu 2015; Mohammadi 2015; Rana et al. 2015; Tam \& Oliveira 2016). However, Mtebe and Raisamo (2014) found system quality to have a positive significant relationship with system use but no significant relationship with user satisfaction. The researcher, therefore, hypothesised that:

H2a: AV System Quality will positively influence AV System Use

H2b: AV System Quality will positively influence User Satisfaction

\section{Audio-visual service quality}

Service quality (SERVQUAL) is defined as 'the extent to which a user perceives that needs such as reliability, responsiveness, assurance, and empathy are satisfied by system providers' (Delone \& McLean 2003; Hsu \& Lin 2010). Thus, getting support from both administrative staff, IT support unit and faculty, will lead to students accepting and being satisfied with the AV technologies for their learning. During student's seminar series presentations, oral examinations and group discussions, when they run into any difficulty in terms of using the AV technologies, what response do they get from Information Communication Technology (ICT) staff determines the service quality and that is what is being measured. In the context of this study, service quality is renamed 'AV Service Quality' and that is what is being examined. Several studies have found that the relationships between service quality and system use and between service quality and user satisfaction are positively significant (Chen et al. 2015; Hsu \& Lin 2010; Mohammadi 2015; Rana et al. 2015). However, other studies did not find a positive significant relationship between service quality and user satisfaction, although there was a positive significant relationship between service quality and system use (Mtebe \& Raisamo 2014). On the contrary, Tam and Oliveira (2016) revealed that, although the relationship between service quality and user satisfaction is positively significant, that of service quality and system use was found to be insignificant.

The researcher, therefore, hypothesised that:

H3a: AV Service Quality will positively influence AV System Use

H3b: AV Service Quality will positively influence User Satisfaction

\section{Audio-visual system use}

System use (SYSUS) is an indicator of the degree 'to which the stakeholder believes that using a particular system has enhanced his or her job performance, or his or her group's organisation performance' (Delone \& McLean 2003; Seddon 1997). Thus, it is expected that the continued use of $\mathrm{AV}$ technologies in the lecture rooms will enhance the performance of students. Also, once students realise that using the system will translate into some benefits like enhancing their studies and research, which can lead to scoring good grades, it is expected that their satisfaction level will also increase. For this study, system use is renamed 'AV System Use' and that is what is being examined. Several researchers have established that there is a positive significant relationship between system use and user satisfaction as well as between system use and net benefits (Lwoga 2014; Mtebe \& Raisamo 2014; Tam \& Oliveira 2016). The researcher, therefore, hypothesised that:

H4: AV System Use has a positive significant relationship with User Satisfaction of AV technologies

H5: AV System Use has a positive significant relationship with Net Benefits 


\section{User satisfaction}

Satisfaction is defined as the degree to which a user favourably perceives the overall assessment of the system' (Delone \& McLean 2003; Hsu \& Lin 2010). User Satisfaction (USESAT) is one of the mediators of the relationship between information quality, service quality, system quality and net benefits. A high level of information quality, system quality and service quality is always a good omen to User Satisfaction. Thus, once users are highly satisfied with the system, there is the tendency that it can translate to considerably high benefits. Student satisfaction of the AV technologies in the lecture rooms is expected to translate to them achieving higher grades in their learning and research. A plethora of studies have also found a positive significant relationship between User Satisfaction and Net Benefits (Mtebe \& Raisamo 2014; Tam \& Oliveira 2016). The researcher, therefore, hypothesised that:

H6: Higher level User Satisfaction has a significant positive relationship with Net Benefits

\section{Net benefits}

The Net Benefit (NETBEN) is 'the extent to which the user perceives benefits such as saving time and cost while using the system' (Hsu \& Lin 2010). High system uses and satisfaction is, therefore, expected to translate to the actual benefits accruing to students.

\section{Research methodology}

The study is quantitative and employs the survey technique. The questionnaire has two sections with the first part capturing the demographic details of the respondents. The second part captured data about the constructs measured on a 7-point Likert scale with end points ' 1 = Strongly Disagree' and ' $7=$ Strongly Agree'. The measures for the constructs were adapted from existing literature (Delone \& McLean 2003; Hassanzadeh, Kanaani \& Elahi 2012; Lin 2007; Lwoga 2014; Mtebe \& Raisamo 2014; Ozkan \& Koseler 2009) and modified to suit the context of this study. The constructs were operationalised as follows: AV Information Quality (INFOQUAL), AV System Quality (SYSQU) and AV Service Quality (SERVQUAL) each have five items. Audio-visual System Use (SYSUS), User Satisfaction (USESAT) and Net Benefits (NETBEN) each have four items.

A stratified random sampling technique was used to get a fair distribution amongst the students at all levels (undergraduates to postgraduates). Data collection was performed through hand delivery in classes, and students were given 4 weeks to complete them. Overall, a total of 500 questionnaires were distributed. However, 472 responses were received, given a response rate of $94.4 \%$. This notwithstanding, 40 questionnaires were found to be incomplete; hence, they were excluded for further analysis. A total of 432 valid questionnaires were obtained. Data analysis was performed through SPSS version 22 for the descriptive statistics, whilst IBM's AMOS 22 was used to analyse the measurement and structural model.

\section{Results and findings Sample descriptive analysis}

The demographic characteristics of the respondents, as displayed in Table 1, revealed that out of the 432 participants that were used for this study, 218 of them were male and 214 were female participants (representing 50.5\% and 49.5\%, respectively). Regarding the age distribution of the respondents, the empirical data revealed that students below the age of 20 dominated, occupying a $54.2 \%$, whilst students between the ages of 21-30 years and 31-40 years represented $37.3 \%$ and $8.6 \%$, respectively. It was also revealed that the undergraduate students dominated the sample with $85.6 \%$ compared with $14.4 \%$ graduate students.

\section{Structural equation modelling}

The study lends itself well to an analysis by covariance structural modelling by following the two-step approach outlined by Anderson and Gerbing (1988). In light of this, the first stage of analysis develops and examines the measurement model, whilst the second stage focuses on the evaluation of the structural model.

\section{Measurement model}

Whilst testing the stability of the measurement scale developed using AMOS version 22, confirmatory factor analysis was used with maximum likelihood estimate. Given this, the fitness of the model used for the study was ascertained based on a range of indices. As indicated in Table 2, the initial yield had a poor fit because minimum discrepancy per degree of freedom $(\mathrm{CMIN} / d f)$ was 2.961, GFI $=0.862$, RMSEA $=0.067$, $\mathrm{RMR}=0.123, \mathrm{NFI}=0.853, \mathrm{CFI}=0.897, \mathrm{RFI}=0.833, \mathrm{IFI}=0.898$, AGFI $=0.832, \mathrm{PCFI}=0.790$ and $\mathrm{PNFI}=0.751$. Considering the poor outcome of the initial result, the measurement model was refined by identifying all standard regression estimates that did not exceed 0.7 and all standard multiple correlation (SMC) values that did not exceed 0.5 , as well as modification indices (MI) that showed very 'high covariance between measurement errors accompanied by high regression' weight between these error constructs (Byrne 2013).

After this examination, it was established that one item of INFOQUAL, three items of SERVQUAL, two items of SYSQU, two items of SYSUS, two items of USESAT and one item of NETBEN were found not to meet the acceptable threshold, hence they were removed. The fit indices after purification revealed that the measurement model had a good fit, as shown in Table 3, with the observed data

TABLE 1: Summary of respondent's profile.

\begin{tabular}{llcc}
\hline Variables & Distribution & Frequency & $\mathbf{\%}$ \\
\hline Gender & Male & 218 & 50.5 \\
& Female & 214 & 49.5 \\
Age & Below 20 years & 234 & 54.2 \\
& 21-30 years & 161 & 37.3 \\
\multirow{2}{*}{ Level of study } & 31-40 years & 37 & 8.6 \\
& Undergraduate & 370 & 85.6 \\
& Graduate & 62 & 14.4 \\
\hline
\end{tabular}


(Browne \& Cudeck 1993) as CMIN/DF was 2.523, GIF = $0.939, \mathrm{RMSEA}=0.059, \mathrm{RMR}=0.081, \mathrm{NFI}=0.938, \mathrm{CFI}=0.961$, $\mathrm{RFI}=0.916, \mathrm{TLI}=0.948, \mathrm{IFI}=0.962, \mathrm{AGIF}=906, \mathrm{PCFI}=0.713$

TABLE 2: Result of measurement model fitness.

\begin{tabular}{lccc}
\hline Fit indices & Accepted value & Initial model & Refined model \\
\hline Absolute measure & & & \\
CMIN/df & $\leq 3.000$ & 2.961 & 2.523 \\
RMR & & 0.123 & 0.081 \\
RMSEA & $\leq 0.080$ & 0.067 & 0.059 \\
GIF & $\geq 0.900$ & 0.862 & 0.939 \\
Incremental fit measure & & \\
NFI & $\geq 0.900$ & 0.853 & 0.938 \\
CFI & $\geq 0.900$ & 0.897 & 0.961 \\
TLI & $\geq 0.900$ & 0.883 & 0.948 \\
IFI & $\geq 0.900$ & 0.898 & 0.962 \\
RFI & $\geq 0.900$ & 0.833 & 0.916 \\
Parsimony fit measure & & & \\
AGIF & $\geq 0.800$ & 0.832 & 0.906 \\
PCFI & $\geq 0.500$ & 0.790 & 0.713 \\
PNFI & $\geq 0.500$ & 0.751 & 0.696 \\
\hline
\end{tabular}

RMR, root mean square residual; RMSEA, root mean square error of approximation; GIF, goodness of fit index; NFI, normed fit index; CFI, comparative fit index; TLI, Tucker-Lewis Index; IFI, incremental fit index; RFI, relative fit index; AGIF, adjusted goodness of fit index; $\mathrm{PCFI}$, parsimony comparative of fit index; $\mathrm{PNFI}$, parsimony normed fit index; $\mathrm{CMIN} / d f$ minimum discrepancy per degree of freedom.

\begin{tabular}{|c|c|c|c|c|c|}
\hline Construct & Items & $\begin{array}{l}\text { Factor } \\
\text { loading }\end{array}$ & AVE & $\begin{array}{c}\text { Composite } \\
\text { reliability }\end{array}$ & $\begin{array}{l}\text { Cronbach's } \\
\text { alpha }\end{array}$ \\
\hline \multirow[t]{5}{*}{ INFOQUAL } & - & - & 0.632 & 0.873 & 0.871 \\
\hline & INFOQUAL1 & 0.826 & - & - & - \\
\hline & INFOQUAL2 & 0.823 & - & - & - \\
\hline & INFOQUAL3 & 0.790 & - & - & - \\
\hline & INFOQUAL4 & 0.737 & - & - & - \\
\hline \multirow[t]{3}{*}{ SERVQUAL } & - & - & 0.757 & 0.862 & 0.861 \\
\hline & SERVQUAL2 & 0.827 & - & - & - \\
\hline & SERVQUAL3 & 0.875 & - & - & - \\
\hline \multirow[t]{3}{*}{ SYSUS } & - & - & 0.652 & 0.789 & 0.790 \\
\hline & SYSUS2 & 0.801 & - & - & - \\
\hline & SYSUS3 & 0.814 & - & - & - \\
\hline \multirow[t]{3}{*}{ USESAT } & - & - & 0.574 & 0.729 & 0.727 \\
\hline & USESAT3 & 0.726 & - & - & - \\
\hline & USESAT4 & 0.788 & - & - & - \\
\hline \multirow[t]{4}{*}{ SYSQU } & - & - & 0.598 & 0.816 & 0.815 \\
\hline & SYSQU1 & 0.827 & - & - & - \\
\hline & SYSQU2 & 0.788 & - & - & - \\
\hline & SYSQU3 & 0.700 & - & - & - \\
\hline \multirow[t]{4}{*}{ NETBEN } & - & - & 0.606 & 0.822 & 0.821 \\
\hline & NETBEN1 & 0.764 & - & - & - \\
\hline & NETBEN2 & 0.762 & - & - & - \\
\hline & NETBEN3 & 0.808 & - & - & - \\
\hline
\end{tabular}

and PNFI $=0.696$. Given this, a further modification was not conducted on the model.

The study also examined the objectivity of the psychometric questionnaire in terms of their validity and reliability. The result obtained indicated that the factor loadings of the latent variables reached their acceptable threshold of 0.50 with a critical ratio as low as 1.96 at $p<0.001$ (Byrne 2013). Based on this, the study further examined the construct validity by undertaking two reliability tests, namely, Cronbach's alpha (CA) and composite reliability (CR). The result of the reliability test also reached its threshold of acceptance, which is 0.70 for both CR and CA. A further test of convergent validity was conducted by assessing the average variance estimate (AVE). As shown in Table 3, the results of the AVE values were also found to be above the threshold of 0.5 for each of the constructs. Hence, it can be concluded that the measurement model used for the study had significant validity and reliability.

\section{Structural model}

The data used for the study were subjected to further analysis by testing the bivariate relationships that existed amongst the constructs incorporated in the model. Using the SEM technique, a test was conducted on the proposed hypothesis. The result from the test (Table 4) was easily interpreted given that the relationship between two constructs can be easily determined whilst the other constructs are held constant. Given this, in the context of AV technologies, the relationships examined revealed that, although the relationship amongst information quality and system usage has been hypothesised as having a positively significant relationship, the current study revealed the opposite. This is so as the $p$-value of 0.077 is greater than 0.05 . Hence, the hypothesised relationship H1a was found to be insignificant.

Moreover, the path relationship between information quality and user satisfaction was found to be positively significant. The analysis also revealed that system quality had a positively significant relationship between system use and user satisfaction. Therefore, hypotheses $\mathrm{H} 2 \mathrm{a}$ and $\mathrm{H} 2 \mathrm{~b}$ were supported as their $p$-values were less than 0.05 . Furthermore, the result also indicated that the relationships amongst service quality, system use and user satisfaction were also found to be positively significant, thus supporting the hypothesised

TABLE 4: Hypothesis testing result.

\begin{tabular}{|c|c|c|c|c|c|c|}
\hline Hypotheses & Hypothesised path & Standardised estimates & SE & CR & $p$ & Outcome \\
\hline $\mathrm{H} 1 \mathrm{a}$ & INFOQUAL $\rightarrow$ SYSUS & 0.140 & 0.071 & 1.767 & 0.077 & Not supported \\
\hline $\mathrm{H} 1 \mathrm{~b}$ & INFOQUAL $\rightarrow$ USESAT & 0.227 & 0.058 & 3.284 & 0.001 & Supported \\
\hline $\mathrm{H} 2 \mathrm{a}$ & SYSQU $\rightarrow$ SYSUS & 0.190 & 0.076 & 2.378 & 0.017 & Supported \\
\hline $\mathrm{H} 2 \mathrm{~b}$ & SYSQU $\rightarrow$ USESAT & 0.246 & 0.064 & 3.373 & $* * *$ & Supported \\
\hline H3a & SERVQUAL $\rightarrow$ SYSUS & 0.255 & 0.061 & 3.529 & $* * *$ & Supported \\
\hline $\mathrm{H} 3 \mathrm{~b}$ & SERVQUAL $\rightarrow$ USESAT & 0.279 & 0.047 & 4.623 & $* * *$ & Supported \\
\hline H4 & SYSUS $\rightarrow$ USESAT & 0.225 & 0.057 & 3.644 & $* * *$ & Supported \\
\hline H5 & SYSUS $\rightarrow$ NETBEN & 0.098 & 0.066 & 1.472 & 0.141 & Not supported \\
\hline H6 & USESAT $\rightarrow$ NETBEN & 0.810 & 0.097 & 8.888 & $* * *$ & Supported \\
\hline
\end{tabular}

SE, standard error; CR, composite reliability; INFOQUAL, information quality; SERVQUAL, service quality; SYSUS, system use; USESAT, user satisfaction; SYSQU, system quality; NETBEN, net benefit. $* * *, 0.000$. 
relationships $\mathrm{H} 3 \mathrm{a}$ and $\mathrm{H} 3 \mathrm{~b}$ as their $p$-values were less than 0.05 . Also, the result revealed that system usage had a positive significant influence on user satisfaction, indicating that the hypothesised relationship $\mathrm{H} 4$ was also supported as its $p$-value was less than 0.05 . On the contrary, the relationship between system use and net benefits was insignificant. This result indicated that the hypothesised relationship H5 was not supported because its $p$-value of 0.141 was greater than 0.05 . However, as expected, the relationship between user satisfaction and net benefits was found to be positively significant. In lieu of this, the hypothesised relationship H6 was also supported as its $p$-value was less than 0.05 .

\section{Discussion}

Given that the current research sought to examine the effect of AV technologies on teaching and learning in a developing economy context, the researcher examined the phenomenon in a Ghanaian higher educational institution (HEI) by employing the updated DeLone and McLean's (2003) IS Success Model as the theoretical lens. The results from the analysis of this test revealed that two of the relationships were rejected whilst the remaining seven were confirmed or supported. Based on this, hypotheses $\mathrm{H} 1 \mathrm{a}$ and $\mathrm{H} 5$ were rejected, hypotheses $\mathrm{H} 1 \mathrm{~b}, \mathrm{H} 2 \mathrm{a}, \mathrm{H} 2 \mathrm{~b}, \mathrm{H} 3 \mathrm{a}, \mathrm{H} 3 \mathrm{~b}, \mathrm{H} 4$ and $\mathrm{H} 6$ were supported.

Consistent with previous studies (Hu 2015; Mohammadi 2015), the hypothesised relationship amongst information quality (INFOQUAL) and user satisfaction was confirmed. Nonetheless, the result of this study failed to corroborate with the assertion that there is a positive significant relationship amongst information quality (INFOQUAL) and system use (SYSUS). Hence, as argued by Tam and Oliveira (2016), although an individual's perception of accuracy, completeness and timeliness of the information output of AV technologies can lead to user satisfaction, it may not influence the individual's actual usage of the system. The study also supported the argument that there is a positive direct relationship between service quality (SERVQUAL) and both user satisfaction (USESAT) and system use (SYSUS). Thus, the perception that the system would satisfy needs such as responsiveness, assurance, reliability and empathy is important when considering issues relating to system usage (SYSUS) and user satisfaction (USESAT). These findings were found to be consistent with prior studies (Chen et al. 2015; Hsu \& Lin 2010; Rana et al. 2015).

The study also presented and validated the claims on the significant importance of system quality (SYSQU) in the measurement of the success of the IS (Mohammadi 2015; Tam \& Oliveira 2016). Consistent with prior research, this study revealed that system quality (SYSQU) had a positive direct relationship with both system use (SYSUS) and user satisfaction (USESAT). In effect, the result of the current study sought to suggest that the reliability, user-friendliness and range of functionality of AV technologies are critical factors in an individual's evaluation of the utility and satisfaction of the system. Another interesting finding of this study was the positive direct relationship amongst system use (SYSUS) and user satisfaction (USESAT) and the insignificant relationship that exists between system use (SYSUS) and net benefits (NETBEN). This suggests that, although the utilisation of a system might have a significant effect on the satisfaction of users, it might not directly influence the net benefit associated with the use of such systems. This result corroborates the findings of existing studies (Chong, Cates \& Rauniar 2010).

Finally, the study also established that there was a direct positive significant relationship between user satisfaction and net benefits. It can be said that the higher the level of user satisfaction, the higher the net benefits. This implies that the level of a user's expectation being met has a significant impact on the net benefit or the success of the IS. This result is also consistent with other studies that have examined the relationship between user satisfaction and net benefits (Mtebe \& Raisamo 2014; Tam \& Oliveira 2016).

\section{Conclusion and recommendations}

This study sought to explore the effect of AV technologies on teaching and learning through the lens of an updated DeLone and McLean IS Success Model. The result of the study revealed that information quality has a significant influence on user satisfaction, system quality has a positive significant influence on system use and user satisfaction, service quality has a positive significant influence on system use and user satisfaction, system usage has a positive significant influence on user satisfaction, and user satisfaction has a positive significant influence on net benefits. On the contrary, information quality does now have a significant influence on system usage. Equally, system use does not influence net benefits. These results provide key highlights and implications for research and practical development and management of AV technologies in HEIs in developing economies.

Firstly, the study contributes to the existing AV studies, by validating the updated DeLone and McLean IS Success Model, backed with a novel statistical analysis (SEM), to examine the implementation success of AV technologies in an HEI. Also, in terms of practice, the findings revealed that although information quality was not found to have a significant effect on system use, the relationship between information quality and user satisfaction was found to be strongly significant. In light of this, the study recommends that systems designers make full use of the timeliness, usefulness, relevance, completeness and accuracy of the information on the user manual to help increase user satisfaction of AV technologies. Hence, high-quality information provided in the user manual is likely to influence user satisfaction because it would facilitate the teaching and learning process by helping them absorb, internalise and understand the operation of the system.

Secondly, because service quality and system quality were found to be significant factors that influenced both system use and user satisfaction, there should be a deliberate attempt by systems designers to employ measures that would 
improve these factors. This result is a clear indication that reliability, access convenience, acceptable response time and easy operability of AV technologies has a significant influence on the enhancement of teaching and learning in HEIs. Also, this study revealed that amongst the numerous antecedents of service quality and user satisfaction examined, service quality recorded the highest score that explains both variables. Given this, the current study recommends that developers of $\mathrm{AV}$ technologies focus on developing systems that are visually appealing and provides help when necessary. This study also admonishes AV technologies designers to generate a well-organised system that facilitates user self-service and provide an immediate feedback mechanism to help users understand and easily operate it.

Additionally, as HEIs are making a substantial investment in AV learning, the institutions must derive some benefit from these technologies. The benefit is mainly to enhance the teaching and learning processes, which can lead to churning out more resourceful graduates.

Furthermore, although the rigorous procedure used for analysing the implementation success of AV technologies presented salient contributions, some limitations were acknowledged. Firstly, the current study focused on one institution and targeted a specific group of students. This makes it difficult for the findings to be generalised across different user groups. Secondly, the study admonishes future researchers to validate the proposed model in the different user populations. Lastly, future studies should consider conducting a longitudinal study because it may enhance the readers' understanding of the causal factors and their interrelationships with the other variables of the AV technologies implementation success.

\section{Acknowledgements}

\section{Competing interests}

The author declares that he has no financial or personal relationship that may have inappropriately influenced him in writing this article.

\section{Author's contributions}

I declare that I am the sole author of this research article.

\section{Ethical consideration}

This article followed all ethical standards for carrying out research without direct contact with human or animal subjects.

\section{Funding information}

This research received no specific grant from any funding agency in the public, commercial or not-for-profit sectors.

\section{Data availability statement}

Any data that support the findings of this study are included within the article.

\section{Disclaimer}

The views and opinions expressed in this article are those of the author and do not necessarily reflect the official policy or position of any affiliated agency of the author.

\section{References}

Akhmetshin, E.M., Ibatullin, R.R., Gapsalamov, A.R., Vasilev, V.L. \& Bakhvalov, S.Y., 2019, 'Audiovisual aids application in the secondary-level vocational education establishments', International Journal of Educational Management 33(2), 374-392. https://doi.org/10.1108/IJEM-02-2018-0082

Anderson, J.C. \& Gerbing, D.W., 1988, 'Structural equation modeling in practice: A review and recommended two-step approach', Psychological Bulletin 103(3), 411-423. https://doi.org/10.1037/0033-2909.103.3.411

Asadi, F. \& Berimani, S., 2015, 'The effect of audio-visual materials on Iranian second grade high school students' language achievement', International Journal of Language and Linguistics 3(2), 69-75. https://doi.org/10.11648/j.ijll.20150302.15

Ashaver, D. \& Igyuve, S.M., 2013, 'The use of audio-visual materials in the teaching and learning processes in colleges of education in Benue State-Nigeria', IOSR Journal of Research \& Method in Education 1(6), 44-55. https://doi.org/ 10.9790/7388-0164455

Browne, M.W. \& Cudeck, R., 1993, 'Alternative ways of assessing model fit', in K.A. Bollen \& J.S. Long (eds.), Testing structural equation models, pp. 136-162, Sage, Beverly Hills, CA.

Byrne, B.M., 2013, Structural equation modeling with LISREL, PRELIS, and SIMPLIS: Basic concepts, applications, and programming, Psychology Press, Mahwah, NJ.

Chavan, S.K., Chavan, K.D., Giri, P.A. \& Jogdand, S.S., 2014, 'Perceptions of medical students regarding use of audio-visual aids in lecture delivery', IOSR J Research \& Method in Education 4(4), 28-32. https://doi.org/10.9790/7388-04452832

Chen, J.V., Jubilado, R.J.M., Capistrano, E.P.S. \& Yen, D.C., 2015, 'Factors affecting online tax filing-An application of the IS success model and trust theory', Computers in Human Behaviour 43, 251-262. https://doi.org/10.1016/j.chb. 2014.11.017

Chong, H., Cates, D. \& Rauniar, R., 2010, 'Validity of Delone and Mclean's E-commerce model in B2C student loan industry', Journal of International Technology and Information Management 19(1), 75-95. https://doi.org/ 10.1504/IJEB.2009.023611

DeLone, W.H. \& McLean, E.R., 1992, 'Information systems success: The quest for the dependent variable', Information Systems Research 3(1), 60-95. https://doi. org/10.1287/isre.3.1.60

Delone, W.H. \& McLean, E.R., 2003, 'The DeLone and McLean model of information systems success: A ten-year update', Journal of Management Information Systems 19(4), 9-30. https://doi.org/10.1080/07421222.2003.11045748

De Sousa, L., Richter, B. \& Nel, C., 2017, 'The effect of multimedia use on the teaching and learning of social sciences at tertiary level: A case study', Yesterday and Today (17), 1-22. https://doi.org/10.17159/2223-0386/2017/n17a1

Hsu, C.L. \& Lin, J.C.C., 2010, 'A study of the adoption behaviour for In-Car GPS navigation systems', International Journal of Mobile Communications 8(6), 603-624. https://doi.org/10.1504/IJMC.2010.035480

$\mathrm{Hu}, \mathrm{X} ., 2015$, 'Effectiveness of information technology in reducing corruption in China: A validation of the DeLone and McLean information systems success model', The Electronic Library 33(1), 52-64. https://doi.org/10.1108/EL-112012-0148

Ibe, E. \& Abamuche, J., 2019, 'Effects of audio-visual technological aids on students' achievement and interest in secondary school biology in Nigeria', Heliyon 5(6), e01812. https://doi.org/10.1016/j.heliyon.2019.e01812

Jose, P., Thaha, F., Varghese, K. \& Poomali, A., 2019, 'Impact of lecture delivery by using PowerPoint presentation and black board and chalk in second year MBBS students in pharmacology', International Journal of Basic \& Clinical Pharmacology 8(2), 316. https://doi.org/10.18203/2319-2003.ijbcp20190153

Kumar, A., Singh, R., Mohan, L. \& Kumar, M.K., 2013, 'Students' views on audio visual aids used during didactic lectures in a medical college', Asian Journal of Medical Sciences 4(2), 36-40. https://doi.org/10.3126/ajms.v4i2.8031

Lari, F.S., 2014, 'The impact of using PowerPoint presentations on students' learning and motivation in secondary schools', Procedia-Social and Behavioural Sciences 98(3), 1672-1677. https://doi.org/10.1016/j.sbspro.2014.03.592

Lwoga, E., 2014, 'Critical success factors for adoption of web-based learning management systems in Tanzania', International Journal of Education and Development Using ICT 10(1), 4-21.

Mansourzadeh, N., 2014, 'A comparative study of teaching vocabulary through pictures and audio-visual aids to young Iranian EFL learners', Journal of Elementary Education 24(1), 47-59.

Mathew, N.G. \& Alidmat, A.O.H., 2013, 'A study on the usefulness of audio-visual aids in EFL classroom: Implications for effective instruction', International Journal of Higher Education 2(2), 86-92. https://doi.org/10.5430/ijhe.v2n2p86

Mohammadi, H., 2015, 'Investigating users' perspectives on e-learning: An integration of TAM and IS success model', Computers in Human Behaviour 45, 359-374. https://doi.org/10.1016/j.chb.2014.07.044

Mtebe, J.S. \& Raisamo, R., 2014, 'A model for assessing learning management system success in higher education in sub-Saharan countries', The Electronic Journal of Information Systems in Developing Countries 61(1), 1-17. https://doi.org/ 10.1002/j.1681-4835.2014.tb00436.x 
Nirmalya, S., Kaushik, T. \& Rituparna, D., 2015, 'Students' opinion towards audiovisual aids used in lecture classes', Hindu 92, 93-99.

Ode, E.O., 2014, 'Impact of audio-visual (AVS) resources on teaching and learning in some selected private secondary schools in Makurdi', International Journal of Research in Humanities, Arts and Literature 2(5), 195-202.

Rana, N.P., Dwivedi, Y.K., Williams, M.D. \& Weerakkody, V., 2015, 'Investigating success of an e-government initiative: Validation of an integrated IS success model', Information Systems Frontiers 17(1), 127-142. https://doi.org/10.1007/s10796-014-9504-7

Rasul, S., Bukhsh, Q. \& Batool, S., 2011, 'A study to analyze the effectiveness of audiovisual aids in teaching learning process at university level', Procedia-Social and Behavioural Sciences 28, 78-81. https://doi.org/10.1016/j.sbspro.2011.11.016

Santos Espino, J.M., Afonso Suárez, M.D. \& González-Henríquez, J.J., 2020, 'Video for teaching: Classroom use, instructor self-production and teachers' preferences in presentation format', Technology, Pedagogy and Education 29(2), 147-162. https://doi.org/10.1080/1475939X.2020.1726805
Seçer, Ş.Y., Şahin, M. \& Alcı, B., 2015, 'Investigating the effect of audio-visual materials as warm-up activity in Aviation English courses on students' motivation and participation at high school level', Procedia-Social and Behavioural Sciences 199, 120-128. https://doi.org/10.1016/j.sbspro.2015.07.495

Seddon, P.B., 1997, 'A respecification and extension of the DeLone and McLean model of IS success', Information Systems Research 8(3), 240-253. https://doi.org/ 10.1287/isre.8.3.240

Spencer, K., 2017, The psychology of educational technology and instructional media, Routledge, London.

Tam, C. \& Oliveira, T., 2016, 'Understanding the impact of m-banking on individual performance: DeLone \& McLean and TTF perspective, Computers in Human Behaviour 61, 233-244. https://doi.org/10.1016/j.chb.2016.03.016

Waheeda, S. \& Murthy, K.S., 2015, 'A comparative study of blackboard teaching with PowerPoint teaching in 1-year medical students', National Journal of Basic Medical Sciences 6(1), 11-13. 